Misoprostol and the debate over off-label drug use. Weeks AD, Fiala C, Safar P. Br J Obster Gynaecol 2004; 112: 269-272

This Commentary discusses the use of drugs outside the provisions of their licence with particular reference to misoprostol. The authors pate that many drugs of proven efficacy are licensed, for example, betamethasone to prevent neonatal respiratory distress syndrome, and clindamycin in pregnancy, although both are included in Royal College of Obstetricians and Gynaecologists (RCOG) Guidelines. Furthermore, a survey in 2000 found that $46 \%$ of all drug prescriptions in European paediatric wards were off-licence. One is former frequen former frequent long-term use of Depomany years before it was licensed for such use.

With regard to misoprostol an interesting situation exists. It has long been licensed for the prevention and treatment of gastroduodenal ulcers but its use in reproductive health is not licensed in the UK or the USA. It is, however, widely recommended for the teatment of mised the induction of and incomplete abortion, the induction of abortion, induction of labour and for cervica preparation before uterine instrumentation

The authors comment: “...the major obstacle to widespread use of this drug in obstetrics and gynaecology has been the manufacturer and patent holder, Searle (now incorporated into Pfizer). The US-based company has not applied for licences for any reproductive health indication, despite the abundant literature on its safe and effective use. The reason is probably an effort to avoid potentially damaging discussions about the drug's use for inducing abortion". It seems as if the "pro-life' lobby in the USA is playing a significant role.

Manufacturers are discouraged from obtaining a licence, which is unlikely to significantly increase sales, as the procedure is laborious and expensive costing an average S\$897 million

Although the drug is widely used in some circles, the manufacturer has not been content to cast a blind eye. In 2001 they took the trouble to publish a reminder to practitioners of the limits of the licence. Notwithstanding this, the RCOG and the British National Formulary recommend misoprostol for medical abortion.

The authors claim that the failure to license limits its use in places such as Africa, where the three main causes of maternal mortality haemorrhage, septic abortion and pre-eclampsia could be reduced by the use of this drug. They remind us that the maternal mortality rate in Africa is a staggering one hundred times geater Arica is a staggering than in Europe (1000 per 100000 live birth compared to 10 per 100000 in Europe) Misoprostol is only approved in South Africa, Ghana and Uganda. The alternatives of ergometrine and oxytocin are potentially dangerous, have no effect on the cervix, require intravenous administration and refrigeration - all of which factors are significant drawbacks in an African context

The failure of the manufacturer to provide authoritative guidance has resulted in overdosage causing ruptured uterus. This is facilitated by the existence of only 200 and $100 \mu \mathrm{g}$ dose tablets being the dose for ulcer therapy whereas labour induction requires a 25 or $50 \mu \mathrm{g}$ dosage.

Finally, the authors believe that when assessing if a particular practice would be accepted by a reputable group of one's peers, and therefore beyond the reach of litigation, doctors cannot rely on the UK Medicines and Healthcare products Regulatory Agency. They may be better served by the advice of the Royal Colleges an when possible by the recommendations of the UK's National Institute for Health and Clinical Ex's Nation (NICE) who have not yet pronounced Excellence (NICE) who have not yet pronounced on misoprostol.
Reviewed by Michael Cox, FRCOG, MFFP Obstetrician and Gynaecologist (Retired), Nuneaton, UK

Editor's Note

Readers are referred to the CEU Guidance article on off-licence prescribing that appears on pp 225-242 of this issue of the Journal.

Maintenance of ovulation inhibition with $75 \mu \mathrm{g}$ desogestrel-only contraceptive pill (Cerazette ${ }^{\circledR}$ ) after scheduled 12-h delays in tablet intake. Korver $\mathrm{T}$, Klipping $\mathrm{C}$, HegarMahn D, Duijkers I, van Osta G, Dieben T. Contraception 2005; 71: 8-13

This study was specifically designed to look at the incidence of ovulation in volunteer women who were given Cerazette ${ }^{\circledR}$ for two cycles and asked to miss pills for 12 hours at specific time intervals. The study was a randomised, openlabel, two-centre study. A sample size of 100 was needed to allow for an incidence of 5\% ovulation to be detected. Detection of ovulation was by a raised level of progestogen.

One hundred women completed the two cycles, half of whom missed pills in the first packet and half in the second. There was only one ovulation detected as compared to $30-40 \%$ for other progestogen-only oral contraceptive preparations. After discontinuing the method, the earliest ovulation was at 7 days with an average time of return to ovulation of 17.2 days.

This study illustrates the suppression of ovulation when a woman is using Cerazette and confirms the safety of the 12 -hour rule for missing pills. This makes Cerazette a convenient alternative to combined hormonal contraception containing oestrogen.

Reviewed by Judy Murty, DRCOG, MFFP

SCMO, Contraceptive and Sexual Health Services, Leeds, UK

\title{
termination of pregnancy
}

\section{Respecting a woman's decision...}

A leading charity in the field of reproductive healthcare, Marie Stopes International helps over one third of all women seeking termination of pregnancy services in the UK each year. We work closely with the NHS and also see private referrals.

We are discreet, confidential and supportive and offer expert care and full information. Women who visit us will have a full consultation and assessment and a choice of options including same day consultation and treatment, choice of surgical or medical abortion and choice of anaesthetics.

Patients can rely on our $\mathbf{2 4}$ hour aftercare service and post abortion counselling service.

\section{Call us on 08451203644 - 24 hours}

for a GP information pack or visit www.mariestopes.org.uk 